\title{
COMPARATIVE REAL AND PERMANENT BENEFIT TO THE STUDENT OF LECTURES AND LABORATORY PRACTICE.
}

\author{
W. B. DAY, PH. G.
}

I would certainly not have ventured upon the preparation of a paper covering so broad a field, were it not for the assurance of our chairman, at whose request this paper was prepared, that it would be intended simply as a basis for discussion and that the subject would be restricted to the student of pharmacy. Had the choice been left to me, I think I should have clected as a subject, "Some Thoughts on Teaching," and the discussion then might have become an "experience meeting!"

At the outset, we may safely assume that there is no difference of opinion among pharmaceutical teachers in regard to the great importance--even the absolute necessity of laboratory courses. Few would assign an inferior position to laboratory instruction in valuing the curriculum of the pharmaceutical school.

The chief object of teaching is to train the mind to clear thinking,- the power to forecast what will happen under given conditions. The imparting of information, however necessary or desirable, especially to the professional or technical student, must nevertheless be regarded as of secondary importance.

Laboratory-practise best gives the training which enables the learner to successfully attack new problems, hence its immediate bearing upon actual life, where new problems and new conditions are constantly being presented.

In the laboratory the student learns from his mistakes, and with less serious consequences than in after life. In lecture courses, on the other hand, the lecturer presents information which has, perhaps, cost years of study and preparation and sets this forth in attractive form with demonstrations and explanations such as clarify the subject in hand and make it as simple and as easily grasped as its nature permits. The interest of the learner is aroused, his enthusiasm grows, reference reading is suggested, he is led to a sincere desire to know, which is the hall-mark of the real student.

The dangers of the lecture system arise from this very ease by which information is imbibed. We are all apt to underrate what is easily attained, the surmounting of obstacies, the courage and will-power growing out of effort and the joy of achievement gained over difficulties, are largely lost.

Yet, we must not forget that the instruction in our schools of pharmacy, until within a few decades, consisted exclusively of lectures; and by means of this instruction or through it, many pharmacists of superior professional attainments were developed. If you reply that the drug-store training afforded in those times a more acceptable stibstitute for laboratory-practise than it does at present, I grant the truth of your argument, but not its sufficiency. No one can say which form of discipline is best in every case. So much depends upon the teacher and not less upon the student. Garfield's definition of a university was, "Mark Hopkins on one end of a $\log$ and a student on the other."

We may be sure that when we fail to interest, we fail to educate. The first requisite to success in teaching, is the ability to create or to awaken this desire 
to learn. But to interest, does not mean to amuse, though some pupils seem to incline to this view. A former associate of mine could never escape the feeling that a considerable number of his pupils regarded the carefully prepared and exceedingly interesting experiments, with which he illustrated his lectures in chemistry, as a sort of vaudeville performance.

Unfortunately, many students in schools of pharmacy are studying, not primarily to equip themselves for their life-work, but rather to attain some object which should be of secondary importance-to pass the state examination for license or to secure just sufficient credits to obtain a diploma. Seldom does a class distinguish itself by showing a general interest in the studies all along the line.

One reason for lack of interest by pharmaceutical students, is the opinion held by some pharmacists that success in college does not especially fit the student for a successful career. Occasionally this view has been impressed upon otherwise bright and capable young men, and results in an attitude of cynicism and indifference not easily overcome.

Again, a small proportion of the student-body seem to hold the opinion that when their fees are paid, the teachers should do the rest. They seem to take seriously the words which $\mathrm{Mr}$. Dooley wittily puts in the mouth of the college president who asks the incoming freshman: "What branch iv learnin' wud ye like to have studied f'r ye be our compitint profissors?"

But how much want of real interest is due to causes outside the student, to prosy and uninteresting lectures, to a routine of carelessly-supervised laboratory operations and to dry and formal text-book recitations, which undertake to force set tasks on reluctant youth?

The problems we encounter here will not be solved by sitting down and thinking about them. More intimate and personal contact between teacher and pupil, so that each may better acquire the viewpoint of the other, will be of great help. This implies smaller classes or at least smaller groups and more carefully inspected,--more closely checked,-work, it means more time from both teacher and student.

Rigorous exclusion of incompetent and idle students early in the course will aid wonderfully. As President Nichols of Dartmouth said, "It is difficult to conduct a college which shall be at once an effective training-school for studious men and an infirmary for the treatment of mentai apathy."

However, I believe that students of pharmacy, as a class, will compare favorably with other college students. The great majority attend school to learn, even if their ambitions are too easily satisfied. Students who seek social advantages, or who are interested chiefly in athletics, or whose sole aim is to have "a good time" are not likely to select the schools of pharmacy. With the increasing requirements for entrance, a further improvement in the morale of the student body may be confidently expected.

Thanks largely to the growing appreciation by educators generally, of the advantages of concrete methods over the memory-cramming system which has so long held sway in our elementary schools, I believe that our students are better fitted now than formerly, to appreciate the advantages afforded by the 
laboratory and are less likely to consider its work as made up of "stunts" which have little connection with the general course.

And,--to return to our subject,--from which method of instruction, lectures or laboratory-practise, does the student benefit most? I answer, it depends on the teacher and on the student. But, in general, I think you will agree with me, that lectures which most closely approach the laboratory method, namely those which freely employ demonstration and experiment, are the most efficient, while laboratory-practise which shares some of the lecture methods, if indeed it does not directly accompany or follow a lecture, gives also the best results.

To my mind, the ideal plan is the combination of lectures, recitations and laboratory-practise associated together in each subject and with the teacher allowed much latitude in the assignment of the relative number of hours devoted to each of these means of instruction. I believe that when the present minimum course adopted by our syllabus committee is increased, the hours added should be very largely given to laboratory-practise.

And let us keep in mind the changed conditions now confronting students of pharmacy and anticipate, as we can, the further changes which are near at hand. As Professor Mann has put it aptly, concerning the student in another branch of education, "It is no longer, What does he know?-but, What can he do? No longer, How much can he reproduce?-but, How well can he produce?"

University of Illinois School of Pharmacy.

\section{THE COMPARATIVE ADVANTAGES OF PRACTICAL EXPERIENCE AND GENERAL EDUCATION AS A PRE-REQUISITE OF INSTRUCTION IN A SCHOOL OF PHARMACY.}

DR. HENRY H. RUSBY.

If the pharmacist were a machine, possessing no other intelli-

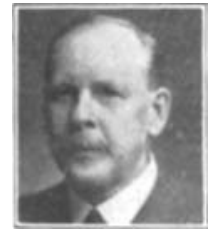
gence than that which represented the maker, and doing his work as a result of having been wound up and set going, it would appear clesirable to leave out of his construction every unnecessary $\operatorname{cog}$ and rivet, lever and spring, so that he would do nothing else than go through the motions for which he was constructed, and would know nothing about what he was doing or why he was doing it. To approach, as nearly as it is possible for a human being to do, to this condition appears to be the conception of the pharmacist's duty which is entertained by a large number of persons connected with the calling. Being a human soul, the real duty of the pharmacist would appear to be to escape just as far from the state suggested, as is consistent with his professional work. The thoughtful person will not fail to recall, that, even in the performance of his ordinary duties, the pharmacist is as often called upon to meet emergencies, and to be thrown upon the resources of his individual intelligence, as are most other members of the community. He will best do this, whose ideas and whose judgment have been the most broadened, and whose intellect has been the most developed; 